\title{
Bacteriophage sensitivity patterns among bacteria isolated from marine waters
}

\author{
K. Moebus \& H. Nattkemper \\ Biologische Anstalt Helgoland (Meeresstation); D-2192 Helgoland, \\ Federal Republic of Germany
}

\begin{abstract}
Phage-host cross-reaction tests were performed with 774 bacterial strains and 298 bacteriophages. The bacteria (bacteriophages) were isolated at different times from water samples collected in the Atlantic Ocean between the European continental shelf and the Sargasso Sea: 733 (258) strains; in the North Sea near Helgoland: 31 (31) strains; and in the Bay of Biscay: 10 (9) strains. Of the Atlantic Ocean bacteria 326 were found to be susceptible to one or more Atlantic Ocean bacteriophage(s). The bacteriophage sensitivity patterns of these bacteria vary considerably, placing 225 of them in two large clusters of bacteriophage-host systems. Taking all into account, 250 of the 326 Atlantic Ocean bacteria are different from each other. This high degree of variation among the bacteria distinguishes microbial populations derived from widely separated eastern and western regions of the Atlantic Ocean. It also sets apart from each other the populations derived from samples collected at successive stations some 200 miles apart, although to a lesser degree. With bacterial populations found from samples collected on the way back and forth between Europe and the Sargasso Sea a gradual change was observed from "western" phage sensitivity patterns to "eastern" ones. Sixty-nine Atlantic Ocean bacteria are sensitive to bacteriophages isolated from the North Sea and the Bay of Biscay; of these only 26 strains are also susceptible to Atlantic Ocean phages. The interpretation of the results is based on the hydrographical conditions prevailing in the northern Atlantic Ocean including the North Sea, and on the assumption that the microbial populations investigated have undergone genetic changes while being transported within water masses from west to east.
\end{abstract}

\section{INTRODUCTION}

Phage typing is a sensitive tool for establishing generic relationships among bacteria. It is widely used in clinical laboratories to identify newly isolated strains within certain species of pathogenic bacteria. Spencer (1957) employed this method with luminous bacteria derived from North Sea fishes (79 bacterial strains) and from "Japanese marine sources" (7 strains). He found statistically significant differences between both groups of bacteria while applying only one bacteriophage isolated from North Sea water with one of the North Sea luminous bacteria.

This phage-host cross-reaction test can also be successfully used with any set of unspecified bacteria for which a sufficiently large number of bacteriophages has been isolated. As reported in a previous paper (Moebus, 1980), for 213 bacterial strains some 250 strains of bacteriophages were isolated from 48 water samples collected in the Atlantic Ocean between the European continental shelf and the Sargasso Sea during spring 1979. This extensive material was used for an investigation basically concerned with the question of differences between the isolated phage-bacteria systems in relation 
to their geographic origin. Included were 40 bacteriophage-host systems previously derived from samples collected in the North Sea near Helgoland and the Bay of Biscay. Taking all into consideration, 774 bacterial strains were phage-typed.

Results concerning geography-related differences in sensitivity to bacteriophages as well as generic relationships among the bacteria will be reported in this paper.

\section{MATERIALS AND METHODS}

\section{Media}

Seawater agar (SWA) contained $5 \mathrm{~g}$ peptone (Difco), $1 \mathrm{~g}$ yeast extract (Difco), $0.1 \mathrm{~g}$ $\mathrm{FePO}_{4}$, and $15 \mathrm{~g}$ agar (Difco) per liter. Soft seawater agar (sSWA) was of the same composition except for its agar concentration which was $0.6 \%$. Seawater broth (SWB/5) was prepared with $1 \mathrm{~g}$ peptone (Difco), $0.2 \mathrm{~g}$ yeast extract (Difco), and $0.1 \mathrm{~g} \mathrm{FePO}_{4}$ per liter. For all media the ingredients were dissolved in a mixture of $75 \%$ aged North Sea water and $25 \%$ distilled water. Their $\mathrm{pH}$ was about 7.6 after autoclaving for $20 \mathrm{~min}$ at $121^{\circ} \mathrm{C}$.

\section{Bacteria}

The bacteria were isolated from North Sea water collected near Helgoland between 1969 and 1978 (H-series), from samples taken in the Bay of Biscay in October 1978 (Bseries), and from 48 samples of Atlantic Ocean water (Moebus, 1980) in spring 1979 (Aseries). They were maintained on SWA slants stored at $5{ }^{\circ} \mathrm{C}$ and grown in roll cultures (1 $\mathrm{rpm}$ ) of $4 \mathrm{ml} \mathrm{SWB} / 5$ each at $25^{\circ} \mathrm{C}$.

\section{Bacteriophages}

Generally, the bacteriophages were derived from the same water sample as their host bacteria. However, among the phages of the $\mathrm{H}$-series which were all isolated between 1976 and 1978, some were found with bacteria selected from our culture collection which were isolated between 1969 and 1976.

High-titre phage stocks (lysates) were prepared as described previously (Moebus, 1980).

\section{Designation of bacteria and bacteriophages}

Bacteria are distinguished by capital letters (referring to the respective series) and consecutive numbers (e.g. A1318). Bacteriophages are designated by the label of their original hosts and consecutive numbers following a stroke (e.g. A1318/1). Bacteriophage mutants are distinguished by an additional number following a hyphen (e.g. A1318/1-1).

\section{Phage-host cross-reaction tests}

Double layer plates containing a $10 \mathrm{ml}$ SWA bottom layer (predried) and $2.5 \mathrm{ml}$ sSWA as over layer were used, the sSWA seeded with about $10^{8}$ bacteria. Immediately after hardening of the sSWA, lysates were dotted on top of the over layers by means of 20 -point inoculators which were flame-sterilized with ethanol after each use. The plates were then incubated at $25^{\circ} \mathrm{C}$ overnight. 


\section{Reading of test plates}

After incubation the plates were checked for spots indicating reaction of the bacteria to lysates. Two types of reaction were distinguished: more or less clear spots due to lysis of bacteria, and more or less turbid spots. The latter were taken into account only if they were distinctly less turbid than the surrounding bacterial lawn.

\section{RESULTS}

Phage-host cross-reaction (PHCR) tests were performed with 298 bacteriophage strains, 258 of which belong to the A-series, 31 to the H-series, and 9 to the B-series. Within the A-series, bacteriophage doublets found from the same sample (intra-sample doublets) had generally been eliminated during preceeding investigations (Moebus, 1980), with the exceptions mentioned below. Intra-sample doublets of bacteria of the Aseries, however, were included in the present investigation.

In a first series of PHCR tests the known 250 host bacteria (including 210 of the Aseries) were used. Because of the encouraging results, an additional 523 bacterial strains of the A-series were subjected to PHCR tests. Among these, 116 strains produced clear or turbid spots with one or more bacteriophage lysates.

Figure 1 compiles the results obtained with the bacteria of the A-series found to be sensitive to lysates of bacteriophages of the A-series. Circles indicate clear lysis, dots represent turbid spots as observed during the PHCR tests or in control spot tests (see below). The numbers of intra-sample doublets of bacteria are given in parentheses according to the present findings. These differ in some cases from previous ones insofar as bacterial strains within larger groups of intra-sample doublets could be differentiated during this investigation. The results found with bacteria and phages isolated from the same sample are shown in individual boxes. The area delimited by the broken line comprises only the results for bacteria and phages derived from samples collected west of the Azores.

As can be seen in Figure 1, the sensitivity marks are distributed rather unevenly. Most conspicuous is the rareness of sensitivity among bacteria isolated from samples collected at Station Nos 465 to 581 to bacteriophages found in samples taken at Station Nos 454 to 464 and 588 to 605 . This indicates that two groups of bacteriophage-host systems were encountered in the Atlantic Ocean. As can be revealed by referring to the cruise track presented by Moebus (1980, Fig. 1), the respective stations were west and east, respectively, of the Azores. Secondly, it is obvious that a considerable portion of bacteria isolated from samples taken between the Bay of Biscay and the Azores (Station Nos 454 to 465 and 602 to 605 ) is susceptible to bacteriophages isolated from samples collected west of the Azores (Station Nos 465 to 581). In contrast, the bacteria derived from samples taken between the Azores and mainland Portugal (Station Nos 588 to 601) are generally insensitive to "western" bacteriophages and in most cases also to phages isolated from samples collected at the more northern stations (Nos 454 to 464 and 602 to 605), comprising a sub-group among the "eastern" bacteria.

The findings concerning this sub-group including those obtained for the last 3 samples (Station Nos 602 to 605) give the impression that from each sample rather distinct sets of bacteriophage-host systems have been derived. They are, of course, related to each other as indicated by sensitivity marks in Figure 1 (lower right) loosely 
scattered around the boxes representing each of the 11 samples proper. Similar observations can be made with the findings obtained from most of the other samples; however, this is more difficult due to the great number of sensitivity marks distributed over large portions of the figure.

To demonstrate relationships on the one hand and differences on the other among the numerous bacteriophage-host systems found, the bacterial strains were grouped according to similarities in phage sensitivity patterns. Generally, the grouping was based on the observation of more or less clear lysis (circles in figures) of the respective bacteria by one or more phages. If linkage between (groups of) bacteria had to be based on lysate activity resulting in turbid spots, the respective findings of the PHCR tests were controlled by spot-testing several dilutions of the lysates in question to make sure that this activity was due to bacteriophage production as indicated by single plaque formation.

This control was necessary since it was found that not all turbid spots observed during the PHCR tests could safely be attributed to phage propagation. In spite of this uncertainty, turbid spots were not excluded from this presentation, even without further control, provided that they had no profound bearing on the present results in general. The problem posed by turbid spots is under present investigation.

The grouping of bacteriophage-host systems resulted in 2 large clusters shown in Figures 2 and 3 , and in 8 small ones. The latter comprise between 2 and 17 bacterial strains and between 4 and 8 bacteriophage strains, including intra- as well as intersample doublets. Forty-two bacteriophage-host systems (including 5 doublets) do not fit in any of these clusters.

In Figures 2 and 3, the strain numbers of bacterial doublets are pooled, with intrasample doublets presented in parentheses. In Figure 2, two or three numbers of phage strains are presented in series indicating doublets. In most cases these doublets were isolated with the same host. They were, however, used in this investigation since differences in several plaque characteristics (e.g. size, number of progeny phages per plaque "unit size", appearance of edge, degree of clearness) were large enough to warrant the expectation that these phages possibly could be differentiated during the PHCR tests as did happen with a number of other phage "doublets" (see phages A45/1 to A45/4 and A139/1 to $139 / 3$, for example).

The cluster shown in Figure 2 includes 160 out of 326 bacterial strains of the A-series found to be sensitive to any of the A-series lysates used. Ninety strains were isolated from "eastern" samples and 70 strains from "western" ones. As can be deduced from the bacterial strain numbers, the members of this cluster were found at many different stations sampled, irrespective of the geographic position. However, bacterial strains isolated from samples collected east of the Azores (strain Nos below 180 and above 1250) are preferentially grouped at the left and right portions of the figure, whereas strains found from samples taken west of the Azores group in the middle of the figure. This indicates that closely related bacteria were predominantly found at stations relatively near to each other. For example, strain Nos A31 to A57 and A1451 to A1504 belong to the geographically adjacent stations 456 and 602 plus 603, respectively, which were in the south-western part of the Bay of Biscay.

In contrast to the findings shown in Figure 2, the second cluster of bacteriophagehost systems presented in Figure 3 comprises a much larger portion of bacterial strains 


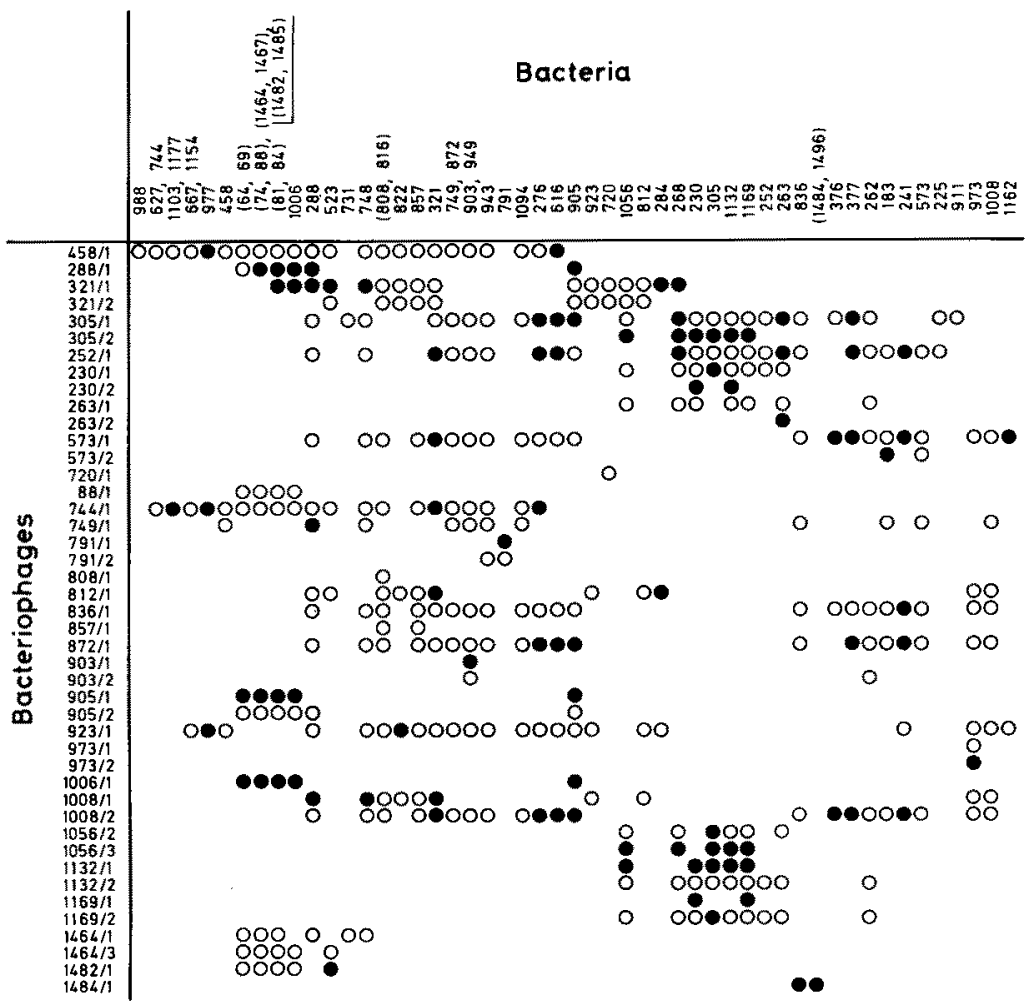

Fig. 3. Bacteriophage sensitivity patterns among A-series bacteria (cluster 2). Other information as for Fig. 2

isolated west of the Azores. Among the 65 bacterial strains in this cluster, only 12 strains representing 4 groups of doublets (Nos A64 to A88 and A1464 to A1496) were found in the eastern part of the Atlantic ocean. Correspondingly, among the 44 bacteriophage strains included in this cluster only 5 were derived from "eastern" samples.

The degree of relationship between the bacteriophage-host systems in the second cluster is generally higher than that between most systems combined in the first one (Fig. 2). As can be seen from Table 1, only $20 \%$ of the bacterial strains included in cluster 1 were sensitive to more than 6 different lysates, whereas with cluster 2 the corresponding value is $61.5 \%$. If based only on results represented by circles in the figures (i. e. clear lysis), the respective figures are $13 \%$ with cluster 1 and $50 \%$ with cluster 2. This difference between both clusters is even expressed by the absolute numbers given in Table 1. Calculations regarding the "western" bacteria, included in cluster 1 only, are also presented in Table 1. They are not much different from those found with the whole cluster. Concerning bacteriophages the relationship of which, of course, can also be deduced from Figures 2 and 3, similar differences between both clusters are obvious.

As mentioned above, in addition to the 2 large clusters of bacteriophage-host systems 8 small ones were found. Among the latter, 6 clusters comprise only bacteria and 
Table 1. Absolute and relative numbers of A-series bacteria reacting to lysates of A-series bacteriophages grouped according to the numbers of lysates active per bacterial strain. 0 , $\bullet$ clear lysis and turbid spots, respectively, in PHCR tests

\begin{tabular}{|c|c|c|c|c|c|c|c|c|}
\hline \multirow{3}{*}{$\begin{array}{l}\text { Bacterial } \\
\text { strains }\end{array}$} & \multicolumn{8}{|c|}{ Number of active lysates } \\
\hline & \multicolumn{4}{|c|}{ o plus $\bullet$} & & \multicolumn{2}{|c|}{ o only } & \multirow[b]{2}{*}{$\geqq 10$} \\
\hline & $1-3$ & $4-6$ & $7-9$ & $\geqq 10$ & $1-3$ & $4-6$ & $7-9$ & \\
\hline & \multicolumn{8}{|c|}{ Cluster 1 (Fig. 2) } \\
\hline \multirow{3}{*}{$\begin{array}{c}\text { No. } \\
\%\end{array}$} & 54 & 74 & 12 & 20 & 83 & 37 & 10 & 8 \\
\hline & 33.8 & 46.2 & 7.5 & 12.5 & 60.2 & 26.8 & 7.2 & 5.8 \\
\hline & \multicolumn{8}{|c|}{ Cluster 2 (Fig. 3 ) } \\
\hline \multirow{3}{*}{$\begin{array}{c}\text { No. } \\
\%\end{array}$} & 17 & 8 & 11 & 29 & 19 & 12 & 20 & 11 \\
\hline & 26.2 & 12.3 & 16.9 & 44.6 & 30.7 & 19.3 & 32.2 & 17.8 \\
\hline & \multicolumn{8}{|c|}{ "Western" bacteria only of cluster 1 (Fig. 2) } \\
\hline No. & 12 & 46 & 5 & 7 & 25 & 27 & 5 & 3 \\
\hline$\%$ & 17.1 & 65.7 & 7.2 & 10.0 & 41.6 & 45.0 & 8.4 & 5.0 \\
\hline
\end{tabular}

phages isolated from samples collected east of the Azores. One cluster contains 11 bacterial strains of which 4 are "western" ones, and 8 bacteriophages, 1 of which is of western origin. The eighth cluster comprises 17 bacteria and 5 phages including only 1 phage-host system isolated east of the Azores.

Figure 4 presents the findings obtained with bacteriophages of the $\mathrm{H}$ - and $\mathrm{B}$-series. Their activity on bacteria of the respective series is demonstrated for comparison only. It is noteable, however, that the bacteriophage strains $H 7 / 2, H 54 / 1$ and $H 84 / 1$ were isolated in 1976 whereas the majority of the other $H$-series phages were found in 1978 .

As can be seen in Figure 4, with 11 out of 31 lysates of the H-series phages and with 1 of the 9 lysates of the B-series phages clear or turbid spots were found during PHCR tests with 69 bacteria of the A-series, the turbid spots outnumbering the clear ones. Two observations are conspicuous. Firstly, there is no overlap in sensitivity to lysates of the $\mathrm{H}-$ and B-series, respectively. Secondly, of 26 bacteria of the A-series, sensitive to A-series lysates (indicated in the figure by dots in front of bacterial strain numbers), 19 reacted to the lysate of the one B-series phage derived from Bay of Biscay water in 1978, versus only 7 strains reacting to lysates of 5 bacteriophages of the H-series.

Finally, it should be noted the 3 bacteria of the $\mathrm{H}$-series and 2 of the $\mathrm{B}$-series were susceptible to 2 and 6 phages of the A-series, respectively, all of which were derived from samples collected west of the Azores.

\section{DISCUSSION}

As mentioned above, the reason(s) why the many phage-bacteria combinations resulted in turbid spots during PHCR tests is (are) not known at the present. Several reasons are conceivable. Lysogenization of the respective bacteria or lysis inhibition 


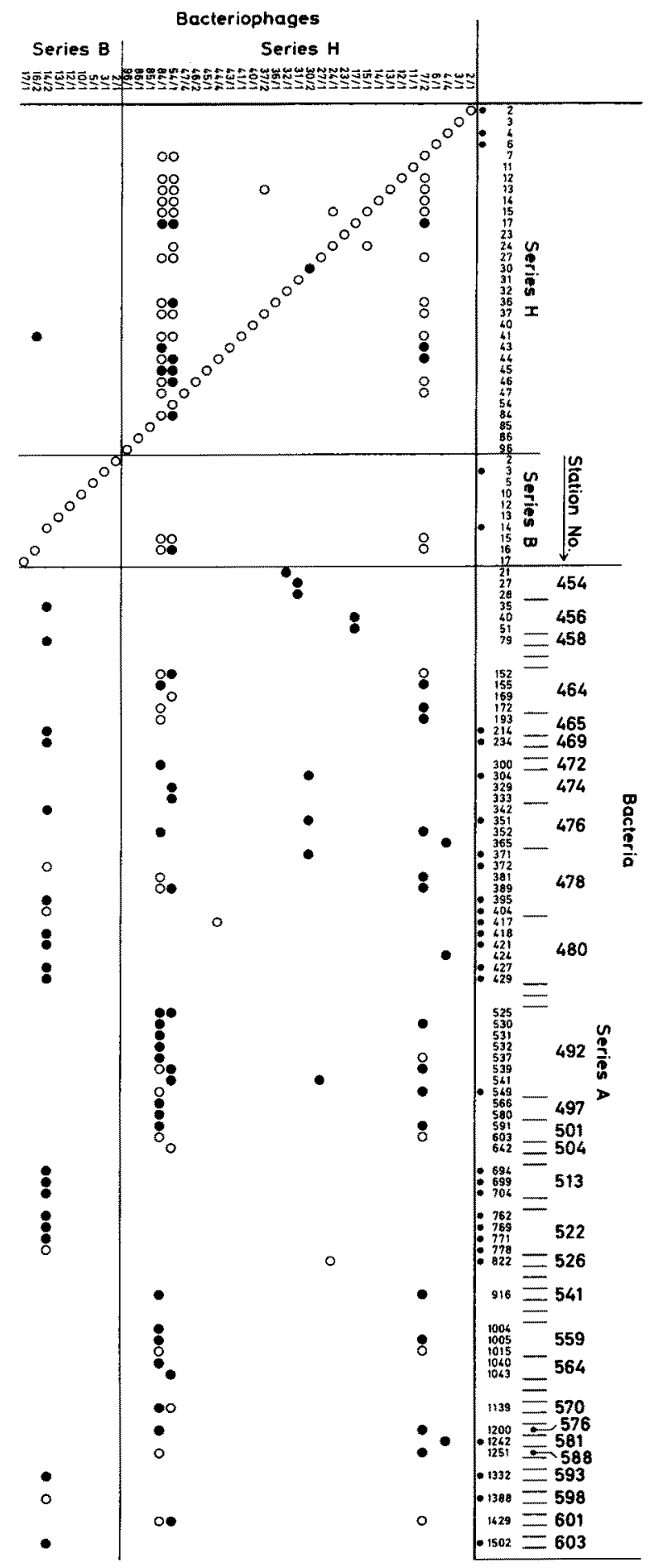

Fig. 4. Sensitivity patterns among bacteria of series $\mathrm{H}, \mathrm{B}$ and $\mathrm{A}$ to bacteriophages of series $\mathrm{H}$ and $\mathrm{B}$. Bacteria found to be sensitive to A-series phages are indicated by dots in front of bacterial strain number. Symbols as in Figure 1 
may be involved. As observed by these authors, turbid lysis may occur in phage-host systems which give rise to very tiny single plaques. However, turbid spots can also be caused by an inhibitory activity of high-titre lysates which does not involve phage propagation, as observed by Blair \& Williams (1961) while phage-typing Staphylococcus aureus. Regarding the results as presented in this paper the following can be stated.

Even if turbid spots had been excluded from presentation, the variation in phage sensitivity patterns among the A-series bacteria would not be much different from that shown in Figures 2 and 3. A relatively small portion of bacterial strains would not be included at all, and in very few cases bacteria now regarded as being different would combine in groups of doublets. However, omission of the turbid spots is not justified since many of them are known to be attributable to phage propagation. Nevertheless, among the remaining turbid spots some may be falsely interpreted as positive results although reading of the test plates was performed with utmost care. The degree of turbidity was recorded, and all turbid spots regarded as doubtful were not taken into account, due to findings of control experiments performed with representative phagebacteria combinations. Therefore, the findings presented in Figures 1 to 3 are expected to be valid to, at least, $90 \%$. The same holds true regarding the results shown in Figure 4 ; however, in this case, the omission of turbid spots would considerably reduce the number of bacterial strains included.

The remaining uncertainty concerning the meaning of turbid spots, however, has no bearing on the discussion of the highly conspicuous results as presented in this paper. These are the considerable variation in bacteriophage-host systems and the strong separation of microbial populations encountered east and west of the Azores, respectively, in the Atlantic Ocean.

According to present knowledge, of the 326 bacterial strains of the A-series found to be sensitive to one or more bacteriophage lysates (Fig. 1) 250 are different from each other. The remaining 76 strains are doublets, comprising 38 each of intra- and intersample doublets. The isolation of intra-sample doublets, of course, was of no interest and it was avoided where possible. Therefore, the number of 38 of such doublets is disappointingly large. In contrast, the same number of inter-sample doublets is astonishingly low but fits the fact that such a large number of bacterial strains of the A-series could be differentiated by PHCR tests.

The great variation in bacteriophage-host systems, many of them being related to each other (Fig. 2 and 3), not only sets apart microbial populations collected from widely separated regions of the Atlantic Ocean but also those derived from samples collected at neighbouring stations. For example, of the 48 stations sampled in the Atlantic Ocean, 23 were in a relatively small area near Bermuda between about $55^{\circ} \mathrm{W}$ to $65^{\circ} \mathrm{W}$ and $32^{\circ} \mathrm{N}$ to $26^{\circ} \mathrm{N}$ (Station Nos 478 to 570 , strain Nos A371 to A1136). Of the 162 "western" bacteria, 106 were derived from this area, the latter comprising 10 intra- and 16 inter-sample doublets.

On the average, less than one inter-sample doublet per sample was found in this area. This is all the more astonishing as only 2 of the 16 inter-sample doublets were obtained from samples collected at stations farther apart than the mean distance between any of the 23 stations successively sampled. The remaining 14 inter-sample doublets were isolated from samples taken at geographically more adjacent stations irrespective of the time interval between sampling. For example, the inter-sample 
doublets A371, A417 and A1108 were derived from samples taken at Station Nos 478 (March 2), 480 (March 3) and 568 (April 1), respectively, the last two stations only a short distance apart. Similar observations were made with 7 other sets of inter-sample doublets, the interval between sampling ranging from 5 to 17 days.

Certainly no far-ranging speculations should be based on these few observations which, however, correspond with, and emphasize, the great diversity among the bacterial populations encountered at any of 23 stations in this relatively small area. As can be seen from Figures 1 and 2, similar variation among bacterial populations was found in samples collected successively in other regions of the Atlantic Ocean.

In bacteriophages of the A-series still greater diversity was observed than among bacteria. As stated above, 250 (about $77 \%$ ) of the 326 sensitive bacterial strains are regarded as being different. The respective figures for bacteriophages are 224 (about $87 \%$ ) of 258 strains. Furthermore, $38(=11.6 \%)$ inter-sample doublets were identified among the bacteria but only $4(=1.6 \%)$ of such doublets among the phages.

In the section "Results" emphasis was placed on the conspicuous difference existing among bacteria isolated east and west of the Azores, respectively, in regard to their bacteriophage sensitivity patterns (Fig. 1). As can be seen from Figure 2, relationships between "eastern" and "western" bacteria were established by the PHCR tests. However, this figure too, shows that the degree of relationship is higher within the group of "eastern" bacteria and that of "western" ones, respectively, than among bacteria of both groups.

Also mentioned before was the sub-group among "eastern" bacteriophage-host systems isolated from samples collected between the Azores and the mainland of Portugal (Station Nos 588 to 601, Fig. 1). As can be seen from Figure 2, relationships have been established in quite a number of cases between bacteria found from these samples (strain Nos 1254 to 1450) and bacteria isolated from other "eastern" or even "western" Atlantic Ocean samples. In contrast to these findings, in the bacteriophages, derived from the samples in question, a very low degree of relationship with phages obtained from other samples was observed, as is deducible from the low number of sensitivity marks related to the 24 different phage strains A1284/1 to A1449/1 in the left and middle portions of Figure 2.

One important aspect of the present results can be interpreted on the basis of the general hydrographical conditions within the part of the Atlantic Ocean visited. As can be seen from Figure 1, numerous bacteria, derived from samples taken between the European continental shelf and the Azores, were found to be sensitive to bacteriophages isolated from samples collected west of the Azores. This can reasonably be accounted for by eastward transport of bacteriophage-host systems in water masses partially originating in the Sargasso Sea (Sverdrup et al., 1970; Dietrich et al., 1975). Logically, this interpretation should also apply to the findings regarding the "western" bacteriophagehost systems only. This is the case, indeed, for bacteria isolated during the cruise from the Azores to Bermuda (Station Nos 465 to 489) are often sensitive to phages isolated from samples successively collected at these stations and from samples of the Sargasso Sea region (Fig. 1). Bacteria from samples collected on the way back from Bermuda to the Azores (Station Nos 565 to 581) can be included in this group.

The remaining bacteria of western origin were found at Station Nos 492 to 564, i.e. from samples collected in a small area within the Sargasso Sea. As indicated by the 
distribution of sensitivity marks in Figure 1, a common feature of these bacteria is a high degree of sensitivity to phages isolated from samples collected at preceeding "western" stations versus a low degree of sensitivity to phages found from samples taken during the cruise from Bermuda to Europe. This conspicuous difference can also be attributed to the prevailing eastward movement of surface water masses, under the reasonable assumption that the ship's speed was higher than that of the water flow.

If the more or less gradual change in bacteriophage sensitivity patterns, as observed in bacterial populations derived from samples successively collected on the way back and forth between Europe and Bermuda, is correctly related to eastward transport of microbial populations, one also has to assume that within these populations changes in terms of genetics take place. Otherwise it would be difficult to interprete the fact that numerous "eastern" bacteria are susceptible to "western" phages but only few "westem" bacteria to "eastern" phages. The considerable variation among the bacteriophagehost systems isolated from the relatively small area south-east of Bermuda (middle portion of Fig. 2, and Fig. 3) on the one hand, and similarities between bacteriophage sensitivity patterns of "eastern" and "western" bacteria as well as seemingly gradual changes in these similarities on the other hand (left portion of Fig. 2) support this view.

Above we pointed out the rather conspicuous delimitation observed between "eastern" and "western" microbial populations in the vicinity of the Azores which cannot easily be interpreted on the basis of the general hydrographical features of the Atlantic Ocean. This delimitation is clearly cut in regard to bacteriophage-host systems isolated on the way from Europe to Bermuda but less distinct for those systems derived from the same region on the way back to Europe (Fig. 1). It is, however, assumed to be an artifact for two reasons: Firstly, the fact that a large portion of bacteria found from Station Nos 462 and 464 are sensitive to phages isolated from preceedingly collected samples can reasonably be assumed to be a random event as it is a unique observation. Secondly, during the ship's first call to Ponta Delgada (Sao Miguel, Azores) a severe storm (Beaufort 11) raged for two days, certainly causing changes in hydrographic conditions in that area, which probably influenced the findings obtained with samples taken west of the Azores immediately afterwards.

Finally, the results based on experiments with bacteriophages of the $\mathrm{H}$ - and $\mathrm{B}$-series on A-series bacteria shall be considered (Fig. 4). As mentioned before, among the 69 Aseries bacteria no overlap was observed in sensitivity to the bacteriophages isolated from the North Sea and the Bay of Biscay during preceeding years. Of these bacteria, 22 reacted to the lysate of phage B14/2, 19 of the latter also being sensitive to phages of the A-series. The remaining 47 bacteria of the A-series reacted to the lysates of $11 \mathrm{H}$-series phages including only 7 strains which are also sensitive to A-series bacteriophages. It also should be noted that of these 69 A-series bacteria only 16 are "eastern" strains.

These findings indicate different relationships between microbial populations from the western Atlantic Ocean and populations from the North Sea and the Bay of Biscay, respectively. They can also be interpreted on the basis of hydrographical data which set apart the two last mentioned regions from each other. Vastly more western Atlantic Ocean water, transported via Gulf Stream and North Atlantic Current, enters the North Sea from north than through the English Channel (Dietrich et al., 1975; Gessner, 1957). This not only helps to explain the relationships between western Atlantic Ocean populations and North Sea populations but also the differences between populations 
from the North Sea and the Bay of Biscay. More attention will be paid to the latter point in the future.

Acknowledgements: The authors are obliged to Dr. J. W. Markham for improving the language of the manuscript.

\section{LITERATURE CITED}

Blair, J. E. \& Williams, R. E. O., 1961. Phage typing of Staphylococci. - Bull. Wld Hith Org. 24, $771-784$.

Dietrich, G., Kalle, K., Kraus, W. \& Siedler, G., 1975. Allgemeine Meereskunde. Borntraeger, Berlin, $593 \mathrm{pp}$.

Gessner, F., 1957. Meer und Strand. VEB Dt. Verl. Wiss., Berlin, 426 pp.

Moebus, K., 1980. A method for the detection of bacteriophages from ocean water. - Helgoländer Meeresunters. 34, 1-14.

Spencer, R., 1957. A possible example of geographical variation in bacteriophage sensitivity. - J. gen. Microbiol. 17, Proc. 11.

Sverdrup, H. U., Johnson, M. W. \& Fleming, R. H., 1970. The Oceans. Prentice-Hall, Englewood Cliffs, N. J, 1087 pp. 